\title{
Henning Tegtmeyer
}

\section{Gott, Geist, Vernunft \\ Prinzipien und Probleme der Natürlichen Theologie}

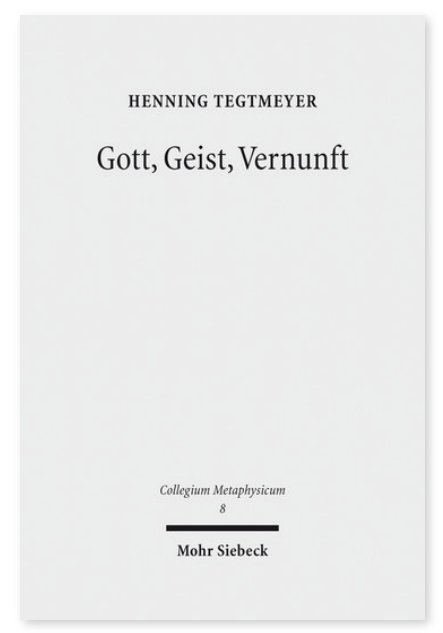

2013. XIII, 391 Seiten. CM 8

ISBN 978-3-16-152921-4 DOI 10.1628/978-3-16-152921-4 eBook PDF 119,00€

ISBN 978-3-16-152584-1

Leinen $119,00 €$
Henning Tegtmeyer plädiert für eine Erneuerung der Natürlichen Theologie als Teildisziplin der Metaphysik und damit der Philosophie. Dass deren Fragestellungen und Probleme unerledigte Aufgaben des Denkens sind, ist seine Hauptthese. Kants wirkmächtige Kritik der Gottesbeweise, des Kernstücks jeder Natürlichen Theologie, erweist sich als nicht allgemeingültig, denn sie trifft nicht die theistischen Argumente Anselms von Canterbury, René Descartes' und des Aquinaten. Auch ambitionierte Versuche einer Reduktion der Theologie auf Anthropologie bei Feuerbach und Bloch scheitern. Die theologischen Ansätze Anselms und Descartes' einerseits, des Thomas von Aquin andererseits müssen als in sich konsistente, aber konkurrierende Paradigmen der Natürlichen Theologie verstanden werden. Da diese Ansätze auf unvereinbaren methodischen Prinzipien zu beruhen scheinen, ergibt sich eine fundamentale methodische Aporie der Natürlichen Theologie insgesamt. Schellings Spätphilosophie wird als Beitrag zur Lösung dieses Problems präsentiert.

Am Schluss der Arbeit erörtert der Autor Folgeprobleme einer möglichen Erneuerung der Natürlichen Theologie, zu denen neben dem Theodizee-Problem vor allem ihr Verhältnis zur doktrinalen Offenbarungstheologie einerseits, zur Religionsphilosophie andererseits gehört, aber auch ihr Ort in einem pluralistischen Religionsverständnis und ihre Stellung im interreligiösen Dialog.

Inhaltsübersicht

I. Feuerbachs These

Theologie als verstellte Selbsterkenntnis des Menschen - Die Hypostasierungsthese - Spekulative Selbsterkenntnis - Gottesund Menschenbild als philosophisches Problem

\author{
II. Die Transzendenz der Gattung \\ Gattungsentwicklung und Transzendenz - Das Wesen des Menschen und die Zukunft - Religion als Repression und \\ Utopiebewusstsein - Die Denkbarkeit des Ultimum
}

\section{Erkenntnis des Transzendenten}

Einwände gegen Anselms Argument - Anselm über das Gute - Das eine Argument - Seinsweise und Attribute des höchsten Denkbaren

IV. Selbstbewusstsein und Gotteserkenntnis

Noch einmal das eine Argument - Selbstbewusstsein - Formale Analogien zwischen Selbstbewusstsein und Gotteserkenntnis - Gotteserkenntnis und Welterkenntnis

V. Naturerkenntnis und spekulative Theologie

Kritik des theologischen Apriorismus - Ontologie als Basis der Theologie - Seinsordnung und Kontingenz - Probleme einer Theologie aus Ontologie

VI. Geist, Vernunft, Natur

Eine Aporie - Glauben, Wissen, Spekulation - Sein und Geist - Identität von Geist und Natur?

VII. Probleme der Natürlichen Theologie

Theodizee als Problem der Natürlichen Theologie - Religionsphilosophie und Natürliche Theologie - Die Vielfalt der Religionen

- Natürliche Theologie zwischen Philosophie und Offenbarungstheologie

Henning Tegtmeyer Geboren 1968; 1990-98 Studium der Deutschen und Slawischen Philologie sowie der Philosophie und Germanistik; 2004 Promotion; 2011 Habilitation; derzeit Associate Professor für Metaphysik und Religionsphilosophie an der Katholieke Universiteit, Leuven.

Jetzt bestellen:

https://mohrsiebeck.com/buch/gott-geist-vernunft-9783161529214?no_cache=1

order@mohrsiebeck.com

Telefon: +49 (0)7071-923-17

Telefax: $+49(0) 7071-51104$ 